Rowatr, E. (1957). J. gen. Microbiol. 17, 297-326

\title{
The Growth of Bordetella pertussis: a Review
}

\author{
By ELIZABETH ROWATT*
}

The Lister Institute of Preventive Medicine, Elstree, Hertfordshire

\begin{tabular}{|c|c|c|c|}
\hline & $\mathrm{CO}$ & NTS & \\
\hline & & & PAGE \\
\hline troduction & 297 & Requirement for cysteine or & \\
\hline lid media & 298 & cystine & 309 \\
\hline Original isolation of the organism & 29 & Bactericidal effects in growth & \\
\hline Modifications of BG medium & 298 & $\therefore \cdot \cdot$ & \\
\hline Effect of $\mathrm{pH}$ value and organic & & The function of glutamic acid & $\mathbf{8 1 0}$ \\
\hline acids & 299 & pH requirements $\cdot \cdot$ & 311 \\
\hline $\begin{array}{l}\text { Media different from BG } \\
\text { medium }\end{array}$ & $30 r>>>>$ & $\begin{array}{l}\text { Utilization of other amino acids } \\
\text { in a complex media }\end{array}$ & 312 \\
\hline Media for isolation of Bordetella & & Requirements in a defined & \\
\hline $\begin{array}{l}\text { pertussis } \\
\text { The elimination of }\end{array}$ & 300 & medium. & 312 \\
\hline Use o & 30 & and profuse growth & 315 \\
\hline Addition of catalase & 302 & Bardetella nertussis & \\
\hline quid media & 30 & Doraetera perilasols & \\
\hline Hornibrook's medium & 303 & Variants, species and genera related & \\
\hline Aeration & 304 & lla $p$ & 318 \\
\hline Cohen \& Wheeler's modification & 30 & Variations in Bordetella pertussis & \\
\hline Vaccine production & 305 & produced by media & 318 \\
\hline $\begin{array}{l}\text { The absolute growth require- } \\
\text { ments of Bordetella pertussis }\end{array}$ & 30 & $\begin{array}{c}\text { Degraded strains of Bordetella } \\
\text { pertussis }\end{array}$ & 318 \\
\hline The effect of starch . & 306 & Formation of ornithine and & \\
\hline Inhibition of growth by fatty & & arginine from glutamate & 320 \\
\hline of growth by sulphur & 306 & $\begin{array}{l}\text { Relationship to other species } \\
\text { Relation of the Bordetella group }\end{array}$ & 321 \\
\hline compounds . & & o other genera & 322 \\
\hline
\end{tabular}

\section{INTRODUCTION}

The existence of the organism causing whooping cough, Bordetella pertussis, was known for some years before it was grown on artificial media; after many attempts Bordet \& Gengou (1906) obtained growth on a solid medium containing glycerinated potato extract and $50 \%(v / v)$ blood. Simpler media were proposed but it was soon realized that an organism growing on these media differed antigenically from that originally isolated and until Hornibrook (1939) described a liquid medium containing amino acids, cysteine and starch, the Bordet-Gengou (BG) medium was the only one suitable for the isolation and continued cultivation of $B$. pertussis. With Hornibrook's and allied media the growth requirements of $B$. pertussis and its metabolism have been investigated by several workers and various inhibitors of its growth identified. Several solid media have been derived from the liquid medium with varying degrees of success, and progress has been made in primary isolation of the

\footnotetext{
* Present address : Central Public Health Laboratory, Colindale Avenue, London, N.W. 9.
} 
organism by the use of the bactericidal substance 4:4'-diamidinodiphenylamine dihydrochloride (M \& B 938). Not all the chemical factors for rapid growth have been isolated and identified, and little is known of the organism's metabolism. Now that it is possible to grow the organism easily this should soon be remedied. This review deals with solid and then with liquid media for isolation and continued propagation, with the metabolism of the organism, followed by its relation to degraded strains, to other Bordetella and to other genera.

\section{SOLID MEDIA}

Original isolation of the organism

Bordet \& Gengou (1906) isolated the causative organism from the sputum of early cases of whooping cough on a glycerinated potato extract containing $50 \%(v / v)$ rabbit or human blood, solidified with agar. Even on this medium, Bordet \& Gengou noted that the organism grew feebly on first isolation. Later it grew more easily and by subculturing many times Klimenko (1908-09) obtained growth on ordinary nutrient agar. Such an organism Bordet \& Sleeswyk (1910) showed to be antigenically different from freshly isolated strains. Later workers, not realizing this difference, modified the original medium by using heated blood (Krumwiede, Mishulow \& Oldenbusch, 1923) or lower concentrations of blood (Debré, Marie \& Pretet, 1928). Some workers, in particular Povitsky (1923) and Kristensen (1927), realized that such media were not suitable for isolation of the organism, but the position was not clear until Leslie \& Gardner (1931) showed that freshly isolated strains were antigenically distinct from strains growing on simpler media. They found four agglutinogens and postulated the existence of four phases containing different combinations of them, phase I being the strain isolated from the patient and phase IV the most degenerate strain. Lawson (1939) could not find strains corresponding to phase II but confirmed the existence of phases I, III and IV. However, he also found a strain with characteristics of phases I and IV. Standfast (1951) showed that phase I and phase III or phase IV characteristics may be present in the same strain, that is, one strain may grow on $\mathbf{5 \%}$ $(\mathrm{v} / \mathrm{v})$ blood agar and be highly virulent to mice, while another is not virulent but will only grow on a Bordet-Gengou medium containing upwards of $20 \%$ $(\mathrm{v} / \mathrm{v})$ blood. Differences of various derived strains will be mentioned later. This loss of virulence and alteration in growth requirements during subculture must be taken into account when media for the growth of Bordetella pertussis are tested, and any medium which will not grow $B$. pertussis on primary isolation should be discarded.

\section{Modifications of BG medium}

The various modifications of Bordet-Gengou medium have been mainly concerned with the time at which the glycerol is added, whether peptone is added, the $\mathrm{pH}$ value of the medium (before blood is added) and the addition of lactic acid. Bordet \& Gengou (1906) extracted the potato with a glycerol solution. Other workers (see Mackie \& McCartney, 1953) added glycerol after 
the extraction. According to Dawson, Farnworth, McLeod \& Nicholson (1951) glycerol was inhibitory at concentrations above $1 \%(w / v)$ and could be omitted altogether without decreasing growth significantly. In earlier work glycerol was thought to be of value in slowing evaporation of the BG medium, but to control the humidity of the incubator is a more satisfactory way to prevent drying. Peptone was originally omitted from the medium to depress growth of other organisms present in sputum (Bordet \&. Gengou, 1906). Mackie \& McCartney (1953) included peptone in their recipe and it.was added to the W.H.O. medium for vaccine production (W.H.O. Report, 1953). However, Dawson et al. (1951) found all peptones to be inhibitory, although Witte peptone and Difco proteose peptone were less so than others. This inhibition is probably due to colloidal sulphur or sulphide (Woiwod, 1954; Proom, 1955). In view of the role of glutamate in the growth of Bordetella pertussis (see below) it would seem reasonable to add some source of this compound; in fact, Dawson et al. (1951) found that both glutamate and aspartate improved growth, and suggested that amino acids may be responsible for the effect of potato extract, of which the filtrate is the active fraction. Bailey (1933) substituted potato starch for some of the potato and claimed that growth was more rapid, but his evidence was scanty. Lacey (1954) also used starch instead of potato extract but he did not compare the two.

\section{Effect of $p H$ value and organic acids}

Povitsky (1923) was the first to notice the effect of the $\mathrm{pH}$ value of solid media; she found that Bordetella pertussis grew better on media with a slightly acid reaction and that Haemophilus influenzae did not grow at this reaction although it grew slightly on the same medium at an alkaline reaction. The use of the acid medium, therefore, made primary isolation of $\boldsymbol{B}$. pertussis easier. The $\mathrm{pH}$ value of the medium was tested before the addition of blood and must have been raised by the addition of blood, except in media initially at $\mathrm{pH} \mathbf{7 \cdot 2}$ $\mathbf{7 \cdot 4}$ which would be unchanged. Unadjusted $\mathrm{BG}$ base at $\mathrm{pH}$ 5.8-6.0 was first used; on it the isolation rate was higher than on the same medium adjusted to pH 7.2-7.4, before addition of blood. A still higher isolation rate was obtained by taking the $\mathrm{pH}$ value of the medium to $5 \cdot 0$ with $1 / 2500$ acetic acid or to $\mathrm{pH} 4.5$ with $1 / 2000$ potassium oxalate. The acids were added after autoclaving since they would otherwise destroy the gelling power of the agar. Even so, material from only five out of seven patients in the first week of the disease yielded $B$. pertussis, and the small number of isolations detracts from the value of an otherwise excellent piece of work. It seems probable that the improvement in growth was due to the $\mathrm{pH}$ value but a specific effect of the anion was not excluded.

Madsen (1925) added about 1/2000 lactic acid to his medium. He adjusted the base to $\mathrm{pH} 7 \cdot 0-7 \cdot 5$ and added blood and lactic acid after autoclaving. Leslie \& Gardner (1931) also added lactic acid but neither of the last two papers records any comparison between media with and without lactic acid. Lacey (1954) used lactate to improve growth in a defined medium + blood which will be considered below; he also adjusted the $\mathrm{pH}$ value of the basal 
medium to $\mathbf{7 \cdot 2}$ before adding blood, and most of the later recipes do this. In the experiments of Ungar et al. (1950) with liquid media, growth of Bordetella pertussis was better at higher $\mathrm{pH}$ values.

\section{Media different from $\boldsymbol{B} \boldsymbol{G}$ medium}

Apart from the media containing charcoal, three media basically different from Bordet-Gengou medium have been described. Silverthorne \& Cameron (1942) added $33 \%(\mathrm{v} / \mathrm{v})$ citrated sheep blood to a basal medium consisting of an aqueous extract of beef liver with salt and agar but without potato. They stated that growth was much more profuse and more rapid than on standard BG medium, but they did not give details. Since they subcultured at 48 $72 \mathrm{hr}$. intervals it seems unlikely that growth was very much more rapid, because on good BG medium single organisms give visible colonies in $72 \mathrm{hr}$., and one normally uses a heavier inoculum than this for subculture; Dawson et al. (1951) found the medium no better than ordinary Bordet-Gengou medium.

Cruickshank \& Freeman (1937) used $20 \%$ (v/v) laked horse blood with $13 \%(v / v)$ horse serum, proteose peptone and heart extract for growth of the organism in quantity; I found that, although growth on this media from a large inoculum might be more profuse than on BG medium, the number of colonies growing from a small inoculum of an exacting strain was generally only one-third and sometimes only one-tenth or a hundredth that on BG medium (Rowatt, unpublished). For large scale work it was not consistently better than BG medium (A.F.B. Standfast, personal communication).

The third medium was that of Barksdale \& Simpson (1934; also see Barksdale, Mullenix \& Fuster, 1941) which contained nutrient agar and potato extract and was reputed to give growth in $24 \mathrm{hr}$. and a 'specific clearing' in the medium in a shorter time. Dr B. W. Lacey (personal communication) was unable to grow Bordetella pertussis on this medium and my experience confirms his.

\section{Media for isolation of Bordetella pertussis}

The W.H.O. report on diphtheria and pertussis vaccination recommended for routine diagnostic purposes a modification of Bordet-Gengou medium, which they attributed to Eldering \& Kendrick (W.H.O. Report, 1953). This medium contained $17 \%$ sheep blood and peptone was not added. Penicillin is often added to the medium since Bordetella pertussis is relatively insensitive to this antibiotic, but the medium is still not completely satisfactory. Lacey (1954) devised a highly selective medium which contained more than $30 \%$ $(\mathrm{v} / \mathrm{v})$ defibrinated horse blood, starch, glycerol and salts and, besides penicillin, M \& B 938 and sodium fluoride. M \& B 938 inhibited most other organisms of the nasopharynx very much more than it inhibited $B$. pertussis; the addition of magnesium ion and some organic acids decreased the inhibition of $\boldsymbol{B}$. pertussis more than that of the other organisms. Some organisms, notably streptococci which are less susceptible to $M \& B 938$, were inhibited by fluoride but this substance inhibited the growth of $B$. parapertussis so that an 
ordinary BG plate had to be used to detect it. Aconitate or lactate was added to improve the growth of $B$. pertussis; it is interesting that here we have a return to the work of Povitsky (1923).

Lacey's medium, although excellent for isolation is even more difficult to prepare than BG medium; it contains eleven extra compounds, and four solutions, including blood, must be added aseptically to the autoclaved base. Although its qualities are thoroughly appreciated it is no longer used by some laboratories because of the difficulty of preparation. The medium at present used by the Central Public Health Laboratory, Colindale (Mr J. D. Atkinson, personal communication) contains peptone, sodium chloride, glycerol, soluble starch and agar. These ingredients are sterilized together and to them are added horse blood to a final concentration of $33 \%(\mathrm{v} / \mathrm{v})$, penicillin and M \& B 938. This medium gives satisfactory growth of Bordetella pertussis and B. parapertussis, and growth of most other organisms is suppressed by the penicillin and $M$ \& B 938. The organic acids and magnesium salts in Lacey's medium make $B$. pertussis much less sensitive to $\mathbf{M} \& \mathbf{B} 938$ and, in their absence, the concentration of this compound must be carefully controlled. When this precaution is taken and sufficient blood is added, the exact composition of the medium is not very important. With Atkinson's medium the isolation rate is slightly lower than with Lacey's medium, but the greater ease of preparation and the fact that B. parapertussis will grow on it make it more suitable for routine work (Mr J. D. Atkinson, personal communication).

\section{The elimination of blood}

Blood and other solutions which must be added to the medium after autoclaving are a constant source of trouble, and several attempts have been made to eliminate blood from the medium. Pollock (1947) used a strain ('Pertussis A') which would grow on $10 \%$ (v/v) blood agar but not on meat digest agar, retaining this growth characteristic through many subcultures. He found that for this strain blood in the solid medium could be replaced by serum, serum albumin or charcoal. Starch had some effect but was not so effective as albumin or charcoal. The unsaturated fatty acids, oleic, linoleic and linolenic, all inhibited the growth of 'Pertussis A' in solid and in liquid media, but the inhibition was overcome by albumin; Pollock suggested that overcoming this inhibition was the function of blood in the growth of the degraded strain. Serum albumin improves the growth of Mycobacterium tuberculosis in the presence of Tween 80 and Davis \& Dubos (1946) showed conclusively that albumin binds inhibitory unsaturated fatty acids firmly and allows growth of the bacillus. 'Pertussis A' would not grow in nutrient broth, but when charcoal or albumin was added the organisms grew quite well. Pretreatment of the medium with charcoal was not enough; the charcoal had to be present during growth. When the charcoal from a medium in which 'Pertussis A' had grown was extracted with methanol, the extract inhibited growth of 'Pertussis A' on agar plates containing albumin, and the inhibitory power was approximately one-hundredth that of oleic acid. The inference is that during growth 'Pertussis A' forms a substance similar to oleic acid, and 
thus inhibits its own growth (Pollock, 1947). I have found oleic acid to be inhibitory to growth of $\boldsymbol{B}$. pertussis, but it is certainly not the only inhibitor (see below). However, albumin and possibly charcoal also neutralize some of the other inhibitors.

A liquid medium solidified with agar would be a convenient substitute for BG medium. However, Verwey, Thiele, Sage \& Schuchardt (1949) found that Bordetella pertussis would not grow in their medium solidified with agar unless blood were added; this is also true of Cohen \& Wheeler's (CW) medium (Mazloum \& Rowley, 1955). On the other hand, B. pertussis grew on CW agar containing $\mathbf{2 . 5} \%(\mathrm{v} / \mathrm{v})$ blood and either serum or red cells could be used at the same concentration, but growth was generally less profuse than on BG medium (Rowatt, unpublished). A preparation of serum albumin c. $95 \%$ pure supported growth but electrophoretically pure serum albumin gave growth only from large inocula. Although CW agar + serum usually gave growth from small inocula, the $\mathrm{CW}$ agar culture was not always satisfactory as an inoculum for liquid $\mathrm{CW}$. An inoculum from $\mathrm{CW}$ agar + blood, for example, gave visible growth after 3 days of incubation in liquid $\mathrm{CW}$ medium, whereas an inoculum from $\mathrm{CW}$ agar + serum took 4 days (Rowatt, unpublished).

\section{Use of charcoal}

Powell, Culbertson \& Ensminger (1951) described a medium for growth of vaccine strains consisting of $\mathrm{CW}$ medium, agar and charcoal. Growth from large inocula was quite good and the vaccine produced was satisfactory (Ensminger, Culbertson \& Powell, 1953). I found that CW agar + charcoal usually enabled Bordetella pertussis to grow from large inocula but not always from small ones. Norite S.G. which was used by Powell et al. (1951), Norite (Harrington Bros.) and activated charcoal (British Drug Houses Ltd.) all gave irregular results (Rowatt, unpublished). Mazloum \& Rowley (1955), using Sutcliffe-Speakman charcoal No. 5, had to add an inoculum of $1 \times 10^{6}$ organisms/drop (technique of Miles \& Misra, 1938) to obtain growth on this medium. Mishulow, Sharpe \& Cohen (1953) used a medium of beef heart extract, peptone and yeast-extract agar to which was added $0.4 \%(\mathrm{w} / \mathrm{v})$ charcoal. They do not give details of yield of organisms but the vaccine they prepared compared well with their standard vaccine. Although the organism could be subcultivated on this medium several times without change of phase, the vaccine was made by growing an inoculum from Bordet-Gengou medium on small quantities of charcoal agar and then on larger quantities of the same medium. I was unable to grow $B$. pertussis on this medium from small inocula.

\section{Addition of catalase}

Mazloum \& Rowley (1955), using a high grade charcoal (Sutcliffe-Speakman No. 5), found that single organisms of Bordetella pertussis did not grow on the medium of Powell et al. (1951). They found that B. pertussis sown on CW agar + charcoal $(0.7 \%, \mathrm{w} / \mathrm{v})$ showed satellite growth near some but not all strains of Staphylococcus aureus (one-third of those tested) and certain other aerobic organisms. A cell-free preparation of $S$. aureus also stimulated growth, 
and although the staphylococcal factor would not diffuse through cellophan, growth occurred with the staphylococcal extract on one side of the cellophan and $\boldsymbol{B}$. pertussis on the other. The extract could be replaced by crude catalase (5\% pure) and $60 \%$ pure catalase at low concentrations, suggesting that growth was being inhibited by hydrogen peroxide. This compound has been implicated as an inhibitor of the growth of several organisms: for example, Pasteurella pestis needs haemin for aerobic but not anaerobic growth on a simple agar medium, suggesting that hydrogen peroxide inhibits growth aerobically (Herbert, 1949). It is probable that growth of $\boldsymbol{B}$. pertussis in liquid media is inhibited by peroxides (Rowatt, 1957).

Mazloum \& Rowley's (1955) medium for the growth of Bordetella pertussis consists of Cohen \& Wheeler's medium with agar, charcoal and a catalase preparation. Catalase does not promote growth in the absence of charcoal (Rowatt, unpublished), although charcoal does to some extent in the absence of catalase (Mazloum \& Rowley, 1955). As an ingredient of a medium catalase is easier to handle than blood, but it is heat labile and destroyed by hydrogen peroxide. A heat-stable compound such as haemin would simplify the making of the medium but this has not yet been tested.

To summarize, solid media for Bordetella pertussis have been developed with two different aims: (i) a medium for isolation such as the original BG, Povitsky's and Lacey's media; (ii) a medium for growing large quantities of organism, such as the media of Cruickshank \& Freeman (1937), Mishulow et al. (1953) and Powell et al. (1951). Besides a high concentration of blood, isolation media generally contain: starch in some form although it has not been proved that this is necessary; a source of amino acids (potato extract, protein hydrolysate or the individual amino acids); and a device for making $B$. pertussis grow better than other organisms of the nasopharynx. This last was accomplished by Bordet \& Gengou by omitting peptone, by Povitsky by lowering the $\mathrm{pH}$ value of the medium and by Lacey by adding penicillin $+\mathrm{M} \& \mathrm{~B} 938+$ organic acids. Lacey's method is the most effective. Mazloum \& Rowley's medium with charcoal and catalase might be sufficient for primary isolation because it will grow $B$. pertussis from single organisms. It should be possible to obtain medium combining these recipes, able to give profuse growth with amino acids and possibly organic acids and suitable for isolation when bactericidal compounds are added.

\section{LIQUID MEDIA}

Bordetella pertussis was found not to grow in liquid media without blood (Lawson, 1939) or tissue extract (Toomey \& McClelland, 1933-34). Such media could not be used for vaccine production for fear of stimulating the formation of antibodies to the other proteins and the bacteria are so much contaminated with protein that they are of little use for metabolic or other tests.

\section{Hornibrook's medium}

In 1939, Hornibrook described a medium for Bordetella pertussis which did not contain blood or tissue extract; it was made of hydrolysed casein, soluble 
starch, salts, cysteine and sometimes yeast extract. Liquid media have since been based on Hornibrook's recipe. In 1940 Hornibrook described another medium containing amino acids + starch + nicotinamide. Nicotinamide is the only firmly established essential growth factor for $B$. pertussis. Hornibrook's first medium was not entirely satisfactory and improvements were suggested. Many of the modifications were alterations of the growth factor source and were dictated by what was readily available locally. For example, Wilson (1945) and Farrell \& Taylor (1945) both used liver extracts. Even so the latter authors obtained only $1.5 \times 10^{10} \mathrm{organisms} / \mathrm{ml}$. On the other hand, Verwey et al. (1949) used nicotinic acid instead of yeast extract and their crop was $2-5 \times 10^{10}$ organisms $/ \mathrm{ml}$. The number of bacteria in cultures as measured by comparison with the American N.I.H. 'Haemophilus pertussis' vaccine standard of $1 \times 10^{10}$ organisms/ml. was five times that found by viable count (Rowatt, 1957), and it is probable that the turbidity of the standard is too low. This should be borne in mind when yields of bacteria are compared, since the numbers quoted may have been measured by different methods.

\section{Aeration}

Hornibrook (1939). incubated cultures in bottles lying on their sides to expose a large surface of medium to the air; other workers have followed this advice, in some cases shaking the bottles to give a higher degree of aeration. Ungar et al. (1950) found that a large area of medium exposed to air increased the rate of growth of virulent strains and increased the yield of bacteria slightly, but bubbling air through the medium killed bacteria of a virulent strain, though it improved growth of an avirulent strain. Although they used an inoculum of $10^{6}-10^{8}$ organisms $/ \mathrm{ml}$. growth in their medium was very slow, continuing until the 10th to 15 th day, and it is possible that during the aeration cysteine was oxidized to give colloidal sulphur or that some inhibitory peroxide was formed (see below). I found (Rowatt, 1957) that, until the organisms reached a concentration of $\mathbf{0 . 1} \mathrm{mg}$. dry wt. $/ \mathrm{ml}$., the rate of shaking did not matter, but above this turbidity the degree of aeration limited the rate of growth; on the other hand rapid shaking was not inhibitory.

\section{Cohen \& Wheeler's modification}

Cohen \& Wheeler (1946) modified Hornibrook's (1939) medium and carried out potency tests on the vaccine obtained. This medium, recommended by the World Health Organization for preparation of Pertussis vaccines (W.H.O. Report, 1953), used Bacto-Casamino Acids (Difco) as source of nitrogen and this, being readily available and similar from batch to batch, gave a possible uniformity to the vaccines prepared. The sodium and calcium concentrations were decreased to make the cultures less granular. However, the decrease in sodium chloride to $0.25 \%(\mathrm{w} / \mathrm{v})$, together with $0.4 \%(\mathrm{w} / \mathrm{v}) \mathrm{NaCl}$ added in the Casamino Acids (technical) gave a final concentration of $0.65 \% \mathrm{NaCl}$ which is higher than that used by Hornibrook (1939).

Cohen \& Wheeler increased the concentration of potassium phosphate to 
improve the buffering power and added ferrous and copper sulphates. The quantity of starch was also increased, but some would be removed when the medium was boiled and filtered. The yeast extract was a dialysate added with the cysteine before autoclaving. The inoculum was transferred from BG medium through increasing volumes of the liquid medium and finally to the vaccine batch giving a crop of $c .1-1.5 \times 10^{10} \mathrm{organisms} / \mathrm{ml}$.

This is one of the few growth media for Bordetella pertussis in which the salt concentrations were worked out experimentally. In most media the salt mixture is arbitrary and vaguely derived from physiological saline. It is unlikely that extra copper is necessary since some is present in Casamino Acids and omission of copper from this medium does not affect growth (Rowatt, unpublished). When making this medium, I have used magnesium sulphate instead of magnesium chloride because the latter is highly deliquescent when hydrated and cannot be dried to a compound of known degree of hydration.

\section{Vaccine production}

With an inoculum from liquid media we found that Cohen \& Wheeler's medium could not be relied upon to give consistent yields of cells (A. F. B. Standfast and co-workers, unpublished). Hornibrook (1939) used an inoculum straight from BG medium but was able to grow the organisms through four subcultures in a liquid medium containing cysteine or glutathione sterilized by filtration. When the cysteine was autoclaved in a complex medium, except in certain ill-defined circumstances, it was necessary to use a large inoculum straight from BG medium to get a good crop (Rowatt, 1957). The large inoculum probably increased the yield of bacteria (Rowatt, 1957) and for routine vaccine production it is generally simpler to autoclave cysteine in the medium and inoculate with the growth from one BG slope $/ 500$ ml. medium, than to add cysteine after autoclaving and use a smaller inoculum. In this way the medium can be autoclaved entire and a contaminated slope will affect only one flask. The quantity of blood in the finished vaccine is negligible. Many workers recommend a high initial $\mathrm{pH}$ value (e.g. Ungar et al. 1950), but I have found (Rowatt, 1957) that the organism grows at the same rate between pH 7.0 and 7.5 and, since alkali is formed during growth, the starting medium should be as acid as possible, i.e. pH 7.0. As explained below, growth is increased by raising the concentration of glutamic acid in the medium. In this laboratory I have obtained crops of ten times the American N.I.H. Haemophilus pertussis vaccine standard of $10^{6}$ organisms $/ \mathrm{ml}$. (2-2.5 mg. dry wt./ml.) in a medium with autoclaved cysteine containing $1 \%$ Benger's tryptic casein hydrolysate $+0.5 \%(\mathrm{w} / \mathrm{v})$ glutamic acid $(72 \mathrm{hr}$. incubation in $500 \mathrm{ml}$. medium) (Rowatt, 1957). Vaccines prepared in this medium gave as good protection in mice as routine vaccines (J. M. Horton, unpublished). The casein hydrolysate used, although less suitable for growth from small inocula, is more suitable than Casamino Acids for growth from large inocula, because the organisms are less inclined to autoagglutinate (Rowatt, unpublished). Growth is limited by lack of one or more factors and possibly by insufficient buffering power of the 
medium. The medium could probably be simplified by omitting copper sulphate. It is not perfect but will regularly give a large crop of bacteria in the antigenic phase desired.

\section{The absolute growth requirements of Bordetella pertussis}

\section{The effect of starch}

One of the most important factors in Hornibrook's original medium was starch. This had been used by Lederle Laboratories for some time for the growth of Bordetella pertussis (Hornibrook, 1939); Weichsel, Rubin, Cohen \& Lapin (1940) reported its use in a meat infusion broth for the growth of a strain which grew on blood agar. Starch could be replaced by $\alpha$ - or $\beta$-dextrin (Hornibrook, 1939) or by amylose (Ungar et al. 1950). Hornibrook (1939) concluded that starch was broken down during growth of $B$. pertussis, because after growth the starch iodine colour was lighter than before, but Ungar et al. (1950) suggested that fatty acids produced by B. pertussis during growth caused the change in colour and that the starch was not used. In view of the apparent inability of $\boldsymbol{B}$. pertussis to use simpler carbohydrates (see below) utilization of starch seems unlikely. Proom (1955) found that starch was necessary for growth of $\boldsymbol{B}$. pertussis in a defined medium, although $B$. parapertussis and B. bronchiseptica grew in the same medium without starch. I found that in a modified Cohen \& Wheeler's medium (CW 1) without starch, B. pertussis grew slowly and replicate flasks became turbid at different times, suggesting that so few organisms grew in each flask that a difference of one viable organism made a significant difference in the time taken to reach a visible turbidity (Rowatt, unpublished). This suggests that starch removes a factor which inhibits initiation and/or continuation of multiplication.

One function of starch in the medium, although probably not the main one, is to reduce precipitation of phosphates during autoclaving; in a medium autoclaved without starch or without Casamino Acids, a heavier precipitate forms. This is discussed below (p. 314).

\section{Inhibition of growth by fatty acids}

It has been suggested that starch annuls inhibition of growth by unsaturated fatty acids; the work of Pollock (1947) has already been mentioned. He obtained a degraded strain of Bordetella pertussis, 'Pertussis A', which grew on $5 \%(w / v)$ blood agar but not on digest agar. The blood could be replaced by serum, serum albumin, charcoal or, less successfully, by starch. When incubated in broth 'Pertussis A' died in about $20 \mathrm{hr}$., but it grew when albumin was added and growth could be obtained when the albumin was added nearly $20 \mathrm{hr}$. after inoculation. The organism grew in broth from small inocula in the presence of charcoal or serum albumin; with starch growth was irregular unless a large inoculum was used. Unsaturated fatty acids inhibited growth in the presence of certain concentrations of albumin, but higher concentrations overcame the inhibition. This suggests that growth of this strain of $B$. pertussis in broth is prevented by unsaturated fatty acids. 
Bordetella pertussis does not normally grow in Cohen \& Wheeler's medium when a small inoculum is used. However, Fisher (1948) managed to obtain growth by treating the casein digest with fat solvents, 'Supercell' and 'Nuchar' and Jebb \& Tomlinson (1955) obtained growth by heating the casein hydrolysate with charcoal at acid and neutral $\mathrm{pH}$ values. I found (Rowatt, unpublished) that the treatment used by Jebb \& Tomlinson did not alter the 'oleic acid' content of Casamino Acids as estimated by Corynebacterium ' $Q$ ' (Pollock, Howard \& Boughton, 1949). Corynebacterium ' $Q$ ' grew sparsely with either charcoal-treated or untreated Casamino Acids, and added oleic acid stimulated growth equally in each medium. Fisher's treatment probably removed fatty acids, but this need not have been the reason why growth occurred.

Pollock (1948) found that during autoclaving of media fatty material was extracted from the cotton wool plugs of the flasks or test tubes, and deposited on the glassware in quantity sufficient to inhibit growth of Bordetella pertussis in the volumes of media normally used. He overcame this difficulty by using for plugging glass wool extracted with methanol; other workers have used aluminium caps (Proom, 1955; Jebb \& Tomlinson, 1955) or small glass beakers (Rowatt, 1955). Small inocula of $B$. pertussis in Cohen \& Wheeler's medium $+\mathrm{a}$ filtered solution of cysteine grew readily in flasks capped with beakers (see below); with cotton-wool plugs growth was merely slowed down, not stopped altogether (Rowatt, unpublished). In this medium, oleic acid $(25 \mu \mathrm{g} . / \mathrm{ml}$.) inhibited growth and the inhibition was not annulled by $1 / 1000$ lysed unwashed red blood cells, an amount which allowed growth from small inocula in Cohen \& Wheeler's medium + autoclaved cysteine, but may have been too little to combat this concentration of oleic acid (Rowatt, 1957). Pollock (1947) found that growth in broth sterilized in flasks with cottonwool plugs (see Pollock, 1948) was inhibited by $4 \mu \mathrm{g}$. oleic acid/ml. when small concentrations of albumin $(0 \cdot 1-0 \cdot 2 \%, \mathrm{w} / \mathrm{v})$ were present. In my medium sterilized in flasks capped with beakers, growth was not inhibited by $5 \mu \mathrm{g}$. oleic acid/ml. (Rowatt, 1957) but this medium contained very little of the fatty acid which supports the growth of Corynebacterium ' $Q$ ' (Rowatt, unpublished) and contained starch which may adsorb fatty acids. It is not surprising that oleic acid has less effect in this medium than in Pollock's (1947) medium.

As already mentioned (p. 301), Pollock (1947) obtained material inhibitory to 'Pertussis A' from charcoal which had been present during growth of the organism in broth; more of this material was obtained from broth in which 'Pertussis A' had grown than from uninoculated broth (Pollock, 1949), Corynebacterium ' $Q$ ', which requires oleic or other unsaturated fatty acid for growth, grew better in a mixed culture with 'Pertussis $A$ ' than in pure culture in the same medium; Corynebacterium ' $Q$ ' also allowed the growth of 'Pertussis A' in broth. This evidence suggested that 'Pertussis A' formed unsaturated fatty acids which inhibited its own growth but stimulated that of Corynebacterium ' $Q$ ' (Pollock, 1949). The formation of fatty acid during growth would cause a progressively increasing inhibition; I did not find this 
in any medium I tried and it seems probable that either the formation of unsaturated fatty acids did not occur or was suppressed in these media, or that the acids were picked up by the starch as soon as they were formed.

\section{Inhibition of growth by sulphur compounds}

In the Cohen \& Wheeler type of medium starch permitted growth from large inocula but not from inocula of less than $1 \times 10^{6}$ organisms $/ \mathrm{ml}$. medium. Small inocula grew when the casein digest had been treated with charcoal (Fisher, 1948; Jebb \& Tomlinson, 1955) or when albumin or blood was added to the medium (Fisher, 1948; Rowatt, 1957). Brucella strains would not grow in media containing Tryptose and the inhibition which could be removed by treating the Tryptose with Norite (Schuhardt, Rode, Oglesby \& Lankford, 1950) was shown to be caused by elementary sulphur formed during the autoclaving of cysteine in the Tryptose (Schuhardt, Rode, Oglesby \& Lankford, 1952). Woiwod (1954) showed that during the autoclaving of cysteine in complex media colloidal copper sulphide and colloidal sulphur were formed. Both sols inhibited the growth of Staphylococcus aureus and colloidal copper sulphide inhibited the growth of Bacillus and Brucella spp. Proom (1955) found that passage of $\mathrm{H}_{2} \mathrm{~S}$ through media containing mixtures of amino acids to remove heavy metals made the media inhibitory to growth of Bordetella pertussis from small inocula. Some casein hydrolysates did not allow growth of $B$. pertussis and this organism too was found to be inhibited by colloidal sulphur and to a lesser extent by colloidal copper sulphide. Bordetella parapertussis and $\boldsymbol{B}$. bronchiseptica were not inhibited by colloidal copper sulphide and phase IV strains of $B$. pertussis were less susceptible than phase I (Proom, 1955). Two very rough strains of B. pertussis (G154E, G 146E) were not inhibited by the quantity of autoclaved cysteine in Cohen \& Wheeler's medium (Rowatt, 1957). Colloidal sulphur or sulphides may be responsible for the inhibitory effect of peptones in solid media (see Dawson et al. 1951).

In the Cohen \& Wheeler type of medium colloidal sulphur formed from autoclaved cysteine was the chief inhibitor of growth of Bordetella pertussis. It acted by preventing multiplication of the inoculum; the organisms remained viable for $c .40 \mathrm{hr}$. and then began to die. With filtered cysteine they began to multiply after 5-18 hr. Cultures containing blood began to multiply slightly more quickly; for example, the lag period with blood might be $12 \mathrm{hr}$. and without, $16 \mathrm{hr}$. (Rowatt, unpublished), but the initial mean generation time was the same in the two cultures (Rowatt, 1957). Cultures containing filtered cysteine solution are therefore growing initially almost at maximum speed.

Inhibition caused by colloidal sulphur in the casein hydrolysate may have been overcome by the cystine or cysteine added (Woiwod, 1954; Proom, 1955); but growth was not slowed down in a medium without added cysteine except for the small quantity added with the yeast extract (Rowatt, 1957). It is possible, therefore, that the charcoal treatment of Casamino Acids used by Jebb \& Tomlinson (1955) may have decreased the formation of inhibitor 
from autoclaved cysteine or lessened its effect. Growth was not inhibited when cysteine was autoclaved in a simple medium with glutamate as the only other amino acid (Jebb \& Tomlinson, 1957).

\section{Requirement for cysteine or cystine}

Besides being the cause of inhibition of growth under certain conditions as described above cysteine is necessary for growth. Hornibrook (1939) showed that cysteine could be replaced by cystine or glutathione but not by methionine; Proom (1955) confirmed this by serial subcultivation. Cysteic acid, homocystine and sulphate are also inadequate (Jebb \& Tomlinson, 1957). In experiments with large inocula, I found (Rowatt, 1957) that added cystine or cysteine increased the total crop of bacteria in media in which glutamate and yeast extract were the only source of nitrogen, i.e. without casein hydrolysate. With filtered cysteine solution, $30 \mathrm{mg}$. cysteine/l. final concentration gave the maximum yield of bacteria, but with cysteine autoclaved in the medium, twice this concentration was needed to give the same yield of bacteria and higher concentrations were inhibitory. Growth with filtered cysteine solution was restricted by lack of another factor.

\section{Bactericidal effects in growth media}

In the previous sections two inhibitors of the growth of Bordetella pertussis have been mentioned, namely unsaturated fatty acids and colloidal sulphur or sulphides. The effect of unsaturated fatty acids uncomplicated by other inhibitors has not been studied. Autoclaved cysteine, the source of colloidal sulphur and sulphides, has a bacteriostatic effect: the viable count did not fall until about $40 \mathrm{hr}$. after inoculation into the inhibitory medium. However, a third inhibitor (Rowatt, 1957) killed the bacteria rapidly: after $15 \mathrm{hr}$., in the presence of this inhibitor, the viable count had fallen to less than a tenth of the original. The inhibitor was found in media containing low concentrations of casein hydrolysate. The inhibition cannot be related to that caused by autoclaved cysteine; the two effects were different in type and substances which annulled one inhibition did not annul the other. The inhibition in low concentrations of Casamino Acids was overcome by red blood cells, but the quantity needed was less than that required to overcome the inhibition by autoclaved cysteine: in some experiments a final dilution of $1 / 100,000$ red blood cells was sufficient. Casamino Acids apparently contained a factor similar to that in red blood cells and at concentrations greater than $0 \cdot 3 \%(w / v)$ this prevented some of the bacteria from being killed. Haemin had some activity and ferrous sulphate sterilized by filtration gave as short a lag period as red blood cells, but autoclaved ferrous sulphate had no effect. These compounds all prevented the lethal effect of some substance in the medium. When insufficient of these substances to give optimal growth was added the colony count fell, sometimes (especially with Casamino Acids or haemin) to a very low value, and the organisms were found to be growing at the normal logarithmic rate as soon as sufficient were present to be measured accurately. This inhibitor did not seem to affect the rate of growth once multiplication began. 
The quantity of haemin, of red blood cells and of $\mathrm{FeSO}_{4}$ necessary to start growth seemed to vary from one batch of medium to another. The variation with haemin was most marked: in some experiments $2.5 \mu \mathrm{g}$. haemin $/ \mathrm{ml}$. medium gave visible growth after $100 \mathrm{hr}$. and in others $0 \cdot 25 \mu \mathrm{g}$. haemin $/ \mathrm{ml}$. gave visible growth in the usual time of $60 \mathrm{hr}$. Since the same Casamino Acid solution and extract of yeast were used for several batches of medium, the only variables were the inoculum and the autoclaving of the medium. It will be shown later that the size of inoculum may affect the rate of growth in later stages.

Hydrogen peroxide (Barry, Conalty, Denneny \& Winder, 1956) and organic peroxides (Woiwod, private communication) may be formed during autoclaving of various media and hydrogen peroxide, and possibly some organic peroxides would be destroyed by blood, haemin or ferrous sulphate. Bordetella pertussis contains catalase (Portwood, 1946), but in the early stages of growth the catalase content of some organisms is low (Cole, quoted by Hinshelwood, 1946; Pinsent, quoted by Herbert, 1949). Thus, although hydrogen peroxide formed by the organisms could probably be destroyed, the catalase content might be too small to destroy a quantity of hydrogen peroxide such as would be formed during autoclaving of the medium. Catalase would not destroy an organic peroxide and inhibition by an organic peroxide seems more likely because cysteine which destroys hydrogen peroxide rapidly did not overcome the inhibition (Rowatt, 1957). However, Mazloum \& Rowley (1955) used catalase to improve growth of $\boldsymbol{B}$. pertussis on a solid medium. More work must be done to identify the inhibitor in liquid media.

\section{The function of glutamic acid}

Bordetella pertussis does not use any of the common sugars either aerobically or anaerobically (see, for example, Jebb \& Tomlinson, 1951) and amino acids must be supplied for its growth. Glutamic acid is one of the amino acids used (Ungar et al. 1950) and when it has disappeared from the medium, growth stops (Jebb \& Tomlinson, 1951). In the early stages of growth in a medium containing $1 \%(\mathrm{w} / \mathrm{v})$ Casamino Acids and yeast extract, the quantity of ammonia formed was, mole for mole, considerably less than the quantity of glutamate used. Later, more ammonia was formed by the deamination of other amino acids. In these experiments (Jebb \& Tomlinson, 1951) large inocula $\left(1 \times 10^{7}\right.$ organisms $/ \mathrm{ml}$.) were used and the yield of bacteria was at least three times that obtained by incubation of small inocula $\left(1 \times 10^{2}\right.$ organisms/ml.) in similar media (Jebb \& Tomlinson, 1955). With large inocula $\left(1 \times 10^{7}\right.$ organisms $/ \mathrm{ml}$.) I also obtained better growth of bacteria (Rowatt, 1957) and a ratio of ammonia formed to glutamate used of 0.6-0.7 (Rowatt, unpublished). However, with small inocula $\left(1 \times 10^{3}\right.$ organisms $/ \mathrm{ml}$. $)$ the ammonia formed was initially approximately equivalent to the amount of glutamate used. Increasing the glutamate concentration increased the crop slightly and suppressed the deamination of other amino acids, especially serine and aspartic acid.

When large inocula were incubated in a medium containing casein hydro- 
lysate (Benger), the quantity of bacteria formed was proportional to glutamate concentration up to $0.3 \%(\mathrm{w} / \mathrm{v})$; the maximum yield $(2.5 \mathrm{mg}$. dry wt. $/ \mathrm{ml}$.) was obtained with $1 \%(\mathrm{w} / \mathrm{v})$ glutamate (Rowatt, 1957). During growth the bacterial-N of a culture was of the same order as the glutamate-N which did not form ammonia, both in the casein hydrolysate + glutamate medium and in a medium from which the casein hydrolysate was omitted, leaving yeast extract as the source of other amino acids. In the casein hydrolysate-free medium growth was limited by lack of a factor or factors present in the casein hydrolysate and stopped before all the glutamate had been deaminated. In this medium the bacterial- $\mathbf{N}$ was approximately equivalent to the nonglutamate amino-N, but according to paper chromatograms the concentration of amino acids, apart from glutamate and alanine, was not significantly altered during growth. The greater part of the bacterial-N must have come from glutamate (Rowatt, 1957). In the medium without casein hydrolysate, after growth had stopped, the remaining glutamate was deaminated with the same ratio of glutamate used to ammonia formed as during growth (Rowatt, unpublished). Paper chromatograms showed an increase in the alanine, valine and leucine spots during this period; unfortunately the amounts were not measured quantitatively nor these amino acids identified directly. Lack of certain amino acids or a growth factor provided by the Casamino Acids but not by the yeast extract must have been stopping growth. However, most of the amino acids must have been synthesized from glutamate; Jebb \& Tomlinson (1957) grew small quantities of the organism in serial culture in a medium containing glutamic acid and cystine as the only amino acids.

Proom (1955) found that in simple mixtures of amino acids glutamate could be replaced by succinate or $\alpha$-ketoglutarate. These compounds are presumably formed from glutamate (see below). In the high glutamate medium with a large inoculum (Rowatt, 1957), the quantity of glutamate (c. 2.0 mg.) necessary for the synthesis of $1 \mathrm{mg}$. dry wt. of organisms contained twice as much nitrogen as the bacteria. Glutamate oxidation, the major metabolic activity of Bordetella pertussis, must be efficient energetically if a weight of bacteria is formed from only twice its weight of glutamate.

\section{pH requirements}

Hornibrook (1939) recommended $\mathrm{pH} 7 \cdot 4$ and Cohen \& Wheeler (1946) $\mathrm{pH} 7 \cdot 2-7 \cdot 3$ for growth of Bordetella pertussis. The medium was adjusted to these values before autoclaving. Ungar et al. (1950) found an optimal $\mathrm{pH}$ value of $7 \cdot 60-7 \cdot 85$, but growth in their medium was very slow and should not be taken as occurring under optimal conditions. Jebb \& Tomlinson (1955) used initial $\mathrm{pH} 7.9$ and Proom (1955) $\mathrm{pH} \mathrm{7.6.} \mathrm{I} \mathrm{found} \mathrm{(Rowatt,} \mathrm{1957)} \mathrm{that} \mathrm{the}$ initial growth rate was the same from $\mathrm{pH} 6 \cdot 9$ to $7 \cdot 7$, although at $\mathrm{pH} 7 \cdot 6 \cdot \mathbf{7 \cdot 7}$ the growth rate became slower earlier than it did at lower $\mathrm{pH}$ values. Consequently I used the lowest possible value, namely $\mathrm{pH} 6 \cdot 9-7 \cdot 0$, which gave a medium capable of taking up a larger quantity of alkali than when the initial $\mathrm{pH}$ was higher. Some of the ammonia in the Casamino Acids was lost 
during autoclaving, so that to obtain a medium containing $1 \%$ Casamino Acids at $\mathrm{pH} \mathrm{6.9-7 \cdot 0}$ it was necessary to adjust to $\mathrm{pH} \mathbf{7 \cdot 2}$ before autoclaving.

It has been stated above that growth of Bordetella pertussis from large inocula in a medium with casein hydrolysate (Benger) was proportional to glutamic acid concentration only up to $0.3 \%(\mathrm{w} / \mathrm{v})$ (Rowatt, 1957). The yield of organisms was greater at 0.5 and $1.0 \%$ than at $0.3 \%(w / v)$ glutamate, but growth was limited possibly by the $\mathrm{pH}$ value of the medium. Media such as these never gave growth above $\mathrm{pH} 8.3$ and usually $\mathrm{pH} 8.2$ was the limiting value, but in the medium without casein hydrolysate growth stopped at pH $7 \cdot 8$ before all the glutamate had been used (Rowatt, unpublished). Casein hydrolysate may contain some of the factor required but not sufficient for crops greater than $\mathbf{2 \cdot 5} \mathrm{mg}$. dry wt. $/ \mathrm{ml}$.

\section{Utilization of other amino acids in a complex medium}

Ungar et al. (1950) found that aspartic acid, serine, glycine, threonine, alanine and proline as well as glutamic acid disappeared from media during growth of Bordetella pertussis. Proom (1955) reported the utilization of cystine serine, glutamic acid, alanine, proline and leucine; aspartic acid, glycine and threonine were not mentioned. He apparently measured these by paper chromatography using butanol + acetic acid as solvent (see Proom \& Woiwod, 1949), and I found (Rowatt, 1955) that serine and aspartic acid travel to the same point in chromatograms of media in this solvent. It is possible therefore that aspartic acid was used.

With $1 \%$ Casamino Acids, I (Rowatt, 1955) did not detect utilization of threonine or leucine, and the cysteine spot was not visible with the butanol+ acetic acid solvent. With $\mathbf{0} \cdot 1 \%$ Casamino Acids, the threonine spot was so faint that it was uncertain whether it was used but the leucine spot was weakened. Alanine was the only spot to alter before the glutamate had been used up; in experiments with low concentrations of amino acids alanine was used but later it sometimes increased (Rowatt, unpublished). In these experiments a small inoculum was used.

With a large inoculum the organism grew in a medium containing glutamate, cysteine and yeast extract as the only nitrogen sources, and in this medium the alanine spot generally increased during growth and so did the valine and leucine spots (Rowatt, unpublished). Valine and methionine have the same $\boldsymbol{R}_{F}$ value in the solvent used and so do leucine and isoleucine. It is possible that only one member of each pair was utilized and with the leucine + isoleucine spot one member may have been utilized and the other synthesized. However, it is equally possible that the same amino acid may be used or synthesized at different times.

\section{Requirements in a defined medium}

Hornibrook (1940) grew Bordetella pertussis in a defined medium containing, besides starch and salts, glutamate, tyrosine, glycine, proline, histidine, arginine and cystine. Large inocula grew but an inoculum dilution was 
reached at which yeast extract became necessary for growth; the yeast extract could be replaced by nicotinamide. Nicotinamide and starch are the only factors for the growth of $\boldsymbol{B}$. pertussis about which all workers are agreed. Hornibrook's (1940) defined medium was not optimal because growth in it could be improved by the addition of casein hydrolysate. Proom (1955) tested this medium (without casein hydrolysate) and found that it would support growth for several subcultures but that alanine was necessary for continued subcultivation. Proom also grew $B$. pertussis through many subcultures in a medium (7 AA) containing asparagine, proline, leucine, alanine, glutamic acid, serine, methionine and cystine. Apart from glutamate and cystine only proline is common to the two media. Proom thought that proline, leucine and alanine were either essential for growth or could only be replaced by complex mixtures of amino acids and almost any combination of three or four amino acids would do to supplement these three.

Jebb \& Tomlinson (1955), on the other hand, found that although nicotinamide was the only essential growth factor for Bordetella pertussis the purines xanthine, hypoxanthine and guanine increased the quantity of growth, and biotin and haemin made growth more rapid. The effect of these factors was first tested in a medium containing charcoal-treated Casamino Acids with an inoculum of $2 \times 10^{2}$ viable organisms $/ \mathrm{ml}$. medium, but a similar relationship was found when glutamate (with cystine) replaced the Casamino Acids, although growth was correspondingly slower (Jebb \& Tomlinson, 1957). With glutamate + nicotinamide + purines + biotin + haemin, the quantity and rate of growth did not alter through two further subcultures. The constant yield of bacteria shows that they were not growing on material carried over in the inoculum and the constant growth rate excludes selection of less exacting strains. In the medium with only glutamate + nicotinamide growth, although very slow, was maintained through four subcultures without decrease in the yield of bacteria. The yield of bacteria in these two media was only $0 \cdot 3 \mathrm{mg}$. dry wt./ml., possibly because these media were inadequately buffered. I have found (Rowatt, unpublished) that in a medium similar to that of Jebb \& Tomlinson (1957) containing 0.01 $\mathrm{m}$-glutamate and $0.1 \%(\mathrm{w} / \mathrm{v})$ Casamino Acids, 0.3-0.5 ml. $0.01 \mathrm{~N}$-alkali was formed during the growth of $0.3 \mathrm{mg}$. dry wt. bacteria. In such a medium the $\mathrm{pH}$ value was taken from $\mathrm{pH} 8 \cdot 2$, the

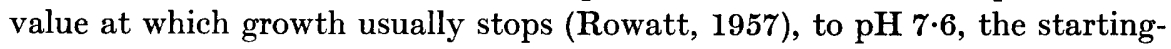
point of Jebb \& Tomlinson's medium, by approximately $0 \cdot 2 \mathrm{ml} .0 \cdot 01 \mathrm{~N}$-acid (Rowatt, unpublished). According to these figures $\mathbf{0 . 3} \mathrm{mg}$. dry wt. organism $/ \mathrm{ml}$. is slightly more than one would expect from Jebb \& Tomlinson's (1957) medium.

The figures of Roberts et al. (1955) for Escherichia coli show that 0.3 mg. dry wt. bacteria contain $c .10 \mu \mathrm{g}$. of each of the majority of amino acids. If we assume that these figures hold for Bordetella pertussis it follows that, to obtain $\mathbf{0 . 3} \mathrm{mg}$. dry wt. bacteria/ml., amino acids which this organism cannot synthesize would have to be added at a concentration of approximately $10 \mu \mathrm{g} . / \mathrm{ml}$. Jebb \& Tomlinson's (1957) medium contains $1.5 \mathrm{mg}$. starch and $1.46 \mathrm{mg}$. glutamic acid $/ \mathrm{ml}$., and in order to add $10 \mu \mathrm{g}$. of any other amino acid 
these compounds would have to contain $1 \%$ of it as contaminant. Since $24 \mu \mathrm{g}$. cystine $/ \mathrm{ml}$. was added, this amino acid would have to contain $42 \%$ of impurity. These facts make it seem unlikely that any other amino acid is required. However, as the cysteine and glutamic acid used were the natural L-isomers, traces of other growth factors might have been added with them. Biotin and $p$-aminobenzoic acid, for example, are notoriously difficult to remove from natural products.

Micro-organisms which cannot synthesize a given growth factor can sometimes grow in the absence of the factor provided other compounds (which may normally be formed through the mediation of the given factor) are added to the medium. Lactobacillus casei, for example, can be grown without added folic acid provided thymine and purine bases are added (Snell, 1951). It is possible that such an effect is responsible for the different results of Proom (1955) and of Jebb \& Tomlinson (1955, 1957). Proom also used some natural amino acids, which may have been contaminated with growth factors. It is difficult to assess the value of Proom's medium because he gives no details of time of incubation or yield of bacteria.

Dawson et al. (1951) using solid media for growth of Bordetella pertussis found that serine inhibited growth, and Jebb \& Tomlinson (1955) found an antagonistic effect of the amino acid in liquid media containing a mixture of amino acids. In their experiments, omission of glycine inhibited growth almost completely, but the yield of organisms was restored to two-thirds of that in complete medium by the omission of serine, proline, and methionine as well as glycine. Omission of leucine or isoleucine decreased growth to three-quarters and omission of these two amino acids together to one-quarter of that in the complete medium; omission of valine + leucine + isoleucine restored growth slightly but not to that in the full medium. This suggests that leucine or isoleucine improves the growth of the bacterium as well as overcoming an antagonism by valine. Proom's (1955) 7 AA medium contains the 'inhibitory' amino acids serine, proline and methionine, but not glycine which overcomes the inhibition; it contains leucine but not isoleucine or valine which is the inhibitory amino acid of this set. According to Jebb \& Tomlinson's (1955) results, omission of glycine should prevent growth, so the results of these workers are again at variance.

Amino acids may be required by bacteria for non-specific functions; for example, buffering the medium (see Mager, Traub \& Grossowicz, 1954) or chelating metals such as iron and preventing their precipitation when the medium is heated. These functions become more important as the medium is simplified. Proom's (1955) statement that several combinations of amino acids would do for growth suggests that they are required for such a nonspecific purpose. Proom's medium may be deficient in metals because the salts are boiled together at $\mathrm{pH} \mathbf{7 \cdot 6}$ without amino acids or starch, both of which tend to lessen the phosphate precipitate formed. When I made this medium with $4.5 \mu \mathrm{g}$. Fe $/ \mathrm{ml}$, the filtrate contained approximately $0 \cdot 1 \mu \mathrm{g}$. $\mathrm{Fe} / \mathrm{ml}$. and sometimes even more iron may be precipitated. Jebb \& Tomlinson (1955) boiled their medium at $\mathrm{pH} 7.9$ and then filtered. Such media are not 
defined so far as inorganic ions are concerned; this method of preparation should be avoided for accurate work. The relative deficiency of iron may have been the reason for my lack of success with these two media (see Rowatt, 1957).

\section{Growth factors needed for rapid and profuse growth}

The medium of Jebb \& Tomlinson (1957) containing starch, glutamate, cystine, nicotinamide and salts may be the simplest medium which supports growth of Bordetella pertussis, but growth is slow and the yield of bacteria small. With small yields the organisms may be growing on impurities in the medium, and it is not certain that they will have the full complement of enzymes or antigens possessed by organisms grown in richer media. From a practical point of view a medium giving rapid profuse growth is needed. A medium containing most amino acids and other compounds ready-made would probably support more rapid growth than one in which these have to be synthesized, but some compounds may cause a disproportionate increase in the rate of growth.

One such factor, or group of factors, for growth of Bordetella pertussis is present in blood and possibly at a low concentration in Casamino Acids (Rowatt, 1957). In media containing low concentrations of Casamino Acids, or a high concentration of Casamino Acids at a high initial $\mathrm{pH}$ value, or with a small inoculum (less than $5 \times 10^{2}$ organisms $/ \mathrm{ml}$.), the organisms grew rapidly with a mean generation time (M.G.T.) of 2.3-2.8 hr. After the 40th to 50th hr. the growth rate decreased and logarithmic growth continued at the new rate with an M.G.T. of 3-5 hr. until growth was almost complete. The primary growth rate was maintained in the presence of 1/100 lysed red blood cells, although not with 1/10,000 lysed red blood cells. I did not do viable counts on cultures containing $1 / 1000$ red blood cells, but a given degree of turbidity appeared more quickly with this concentration of blood than without it and it is probable that enough of the factor or factors was present to keep growth at the primary rate for longer. The secondary growth rate appeared before the concentration of glutamate or ammonia was sufficiently altered to be limiting; it occurred at different $\mathrm{pH}$ values when the initial $\mathrm{pH}$ of the medium was varied, and it was not caused by lack of oxygen because with the conditions used the aeration rate did not limit growth until more than $0 \cdot 1 \mathrm{mg}$. dry wt. organism $/ \mathrm{ml}$. was present. The factor was not nicotinamide, boitin or haemin because the effect was present in media containing these compounds (Rowatt, unpublished). It could not be a mixture of amino acids or growth factors because these were added in the $1 \%$ Casamino Acids and in the yeast extract. It probably was not present in sufficient concentration in serum because media containing serum generally grew more slowly than those containing red blood cells (Rowatt, 1957) and inocula from CW agar with serum grew more slowly than those from CW agar with blood (see p. 302). It may be the factor which increased growth when large inocula were used (see p. 310), but this has not been adequately tested.

The slower overall growth rate in media with added nicotinamide instead of yeast extract and with only glutamic acid and cysteine as amino acids (Jebb 
\& Tomlinson, 1957; Rowatt, 1957) may be due to the time taken to synthesize constituents of the organism. However, I found smaller yields in media in which glutamate replaced Casamino Acids and in some media in which nicotinamide replaced yeast extract. This may have been due to a decrease in amount of organisms formed per unit weight of glutamate, but it may have been due to a deficiency of other factors. If, in a medium giving a small crop of bacteria, the yield can be increased by adding more of a component such as buffer or energy source, other deficiencies may become apparent.

To summarize, media for the growth of Bordetella pertussis must not contain colloidal sulphur or sulphides, unsaturated fatty acids or substances tentatively identified as peroxides. Starch, nicotinamide and cystine or cysteine are essential for growth and the yield of organisms is proportional to the concentration of glutamate, within wide limits. Alkali is formed during growth and consequently the medium must be adequately buffered. Different authors recommended initial $\mathrm{pH}$ values from $\mathrm{pH} 7 \cdot 0$ to $7 \cdot 8$. Most authors recommend mild aeration of the medium. According to Jebb \& Tomlinson $(1955,1957)$ slow growth can be obtained in a medium containing starch, nicotinamide, cystine and glutamate; growth is quicker when purines, haemin and biotin are also added. Proom (1955) found this medium to be inadequate and obtained growth with eight amino acids with nicotinamide as the only growth factor. For rapid profuse growth, constituents of blood, yeast extract and casein hydrolysate should be added, together with factors added with large unwashed inocula (Rowatt, 1957). Large inocula are less sensitive than small inocula to the inhibitory substances mentioned at the beginning of this paragraph.

\section{THE METABOLISM OF BORDETELLA PERTUSSIS}

Knowledge of the metabolism of Bordetella pertussis is slight. It is an aerobic organism, and Fujita \& Kodama (1934) found that a strain growing on blood agar contained cytochromes $a, b, c, d_{1}$, and $d_{2}$ but they did not test a true phase I strain. Portwood (1946) found that most phase I strains had catalase activity, but 14 out of 62 did not. She also stated that rough strains of $B$. pertussis had little or no catalase activity. The two phase IV strains I have tested both decomposed hydrogen peroxide (Rowatt, unpublished). The suspensions of the strains found by Portwood (1946) to be inactive may have been too old (see, for example, Cole, quoted in Hinshelwood (1946)).

Bordetella pertussis does not oxidize or ferment any of the usual sugars. However, it contains both ribonucleic and deoxyribonucleic acid and some polysaccharide (Overend, Stacey, Webb \& Ungar, 1951), and must be able to metabolize the constituents of these compounds sufficiently to incorporate them into the bacterial substance.

The major metabolic activity of Bordetella pertussis is the oxidation of amino acids. Glutamate was the most readily oxidized, but serine, alanine, proline and aspartic acid were also attacked. Ammonia and carbon dioxide 
were formed from serine, alanine and proline in quantities close to those required for complete oxidation (Jebb \& Tomlinson, 1951). The quantity of ammonia formed from aspartic acid was less than the theoretical, but the oxygen uptake and $\mathrm{CO}_{2}$ output were consistent with complete oxidation. Since the aspartic acid oxidizing system was less stable than the others thick suspensions were used which may have contained sufficient keto acid to take up the missing nitrogen. In a medium containing yeast extract, some growth occurred on serine, proline, alanine and aspartic acid, but the crop was only one-third of that with glutamate as the main source of nitrogen (Jebb \& Tomlinson, 1951). Ungar et al. (1950) reported that glycine and threonine disappeared from the growth medium of B. pertussis, but only $30-50 \%$ of the threonine was used; casein contains only $0 \cdot 4 \%$ glycine compared with $2-6 \%$ of most other amino acids (Tristram, 1946). This finding is therefore quite consistent with that of Jebb \& Tomlinson (1951) that threonine and glycine are not oxidized by $\boldsymbol{B}$. pertussis.

When glutamic acid was oxidized the quantities of oxygen used and of ammonia and carbon dioxide formed were less than those required for complete oxidation (Jebb \& Tomlinson, 1951). Acetate, which is formed from glutamate by Haemophilus parainfluenzae (Klein, 1940), was not found and Jebb \& Tomlinson (1951) assumed that the missing nitrogen was built into cell substance. With a nitrogen-containing compound and a large quantity of bacteria this is probably because the cells contain sufficient of the growth factors required; according to Jebb \& Tomlinson (1957) only nicotinamide and cystine need be added to glutamate to give a growth medium. Paper chromatography did not show any amino compounds in the suspension medium after glutamate had been oxidized, but either insufficient of each compound was formed or they were not released from the cells into the medium (Rowatt, 1955).

The first step in oxidation of glutamic acid is usually deamination to $\alpha$-ketoglutaric acid and evidence for this reaction in Bordetella pertussis was produced by Jebb \& Tomlinson (1951). They incubated washed suspensions with glutamic acid in the presence of arsenious oxide, which partially blocks the oxidation of keto acids, and isolated a compound whose 2:4-dinitrophenylhydrazone had the same $\boldsymbol{R}_{F}$ value in two solvents as the derivative of authentic $\alpha$-ketoglutaric acid. $\alpha$-Ketoglutarate was oxidized by washed suspensions about half as rapidly as glutamate. Succinate was oxidized rapidly to begin with and pyruvate was oxidized slowly but oxaloacetate, fumarate, malate and acetate did not alter the rate of oxygen uptake (Jebb \& Tomlinson, 1951). These compounds are usually intermediates in the oxidation of glutamate by the citric acid cycle, but it is possible that they had no effect because they were unable to get to the active centre in the bacteria. Proom (1955) found that succinate and $\alpha$-ketoglutarate replaced glutamate for growth; citrate was active for a few phase I strains but lactate and pyruvate were inactive. Jebb \& Tomlinson (1951) found that lactate was oxidized rapidly at the beginning of incubation but it is possible that this compound, like alanine, is a poor source of energy. Fukumi $e$ al. (1953) found that B. pertussis oxidized 
fumarate, malate, succinate, $\alpha$-ketoglutarate, citrate and acetate; it is not certain that the strains used by them were in phase $I$.

Bordetella pertussis does not contain urease and washed suspensions do not form detectable quantities of arginine or ornithine from glutamate or of pigment from tyrosine and glutamate (Rowatt, 1955).

\section{VARIANTS, SPECIES AND GENERA RELATED TO BORDETELLA PERTUSSIS}

Variations in Bordetella pertussis produced by media

Three variations in antigenic and morphological characters of Bordetella pertussis have been produced by alteration of the growth media. Toomey \& Takacs $(1936,1938)$ changed the normal short rod to a long organism by adapting freshly isolated strains to veal brain agar or chocolate agar at high $\mathrm{pH}$ values. In veal brain broth the organisms were filamentous but became bacillary when returned to veal brain agar. The long forms from chocolate agar could be shortened again by subculture on haemoglobin blood agar (BG) at a lower $\mathrm{pH}$ value. A similar change to a bacillary organism occurred during subculture in horse blood agar, and on this medium the organisms became avirulent and filamentous, although the same strain grown on sheep or human blood agar remained virulent and was coccobacillary. This work has not been repeated and its significance is not clear.

Lacey (1951) found that growth of Bordetella pertussis on a solid medium containing magnesium sulphate ('magnesium organism') instead of sodium chloride ('sodium organism') changed the antigenic structure. The 'magnesium organism ' was not agglutinated by antisera against a 'sodium organism' and antisera against the 'magnesium organism' agglutinated the 'sodium organism' at a lower titre than the 'magnesium organism'. The medium contained $33 \%(\mathrm{v} / \mathrm{v})$ horse blood and consequently approximately $0 \cdot 1 \%(\mathrm{w} / \mathrm{v})$ sodium $/ \mathrm{ml}$. This effect should be borne in mind when any major alteration to the salt content of the medium is contemplated.

Wittler (1951, 1952) obtained L-forms of Bordetella pertussis by ageing, chilling, or by growing inocula of the normal organism on BG plates containing $0.75-1.5 \%(\mathrm{w} / \mathrm{v})$ glycine. The L-forms were small round bodies staining red with Giemsa, and long rods and large dark red or purple masses. In order to obtain the L-forms on plates it was necessary to add $1.5 \%(\mathrm{w} / \mathrm{v})$ glycine: $0.75 \%(w / v)$ glycine did not always give full transformation. When the normal bacillary form was inoculated into mice, small round red forms could be seen in Giemsa stained phagocytes; the change was more complete in immunized than in normal mice.

\section{Degraded strains of Bordetella pertussis}

Leslie \& Gardner (1931) found that Bordetella pertussis could become changed on continued subculture until finally it grew on solid media without blood. Those who have worked with $\boldsymbol{B}$. pertussis will agree that when one is trying to get the organism to grow on digest agar this transformation takes a 
long time. Strains frequently grow on blood agar and it seems that blood agar in different laboratories and even at different times in the same laboratory varies in nutritive value. However, to make a strain grow on meat digest agar it may be necessary to subcultivate up to 400 times and even then the strain may grow poorly and die out. Standfast (1951) showed that strains of B. pertussis may gain one or more phase IV characteristics while retaining some phase I characteristics. Thus, a strain may become ten times less virulent as tested by intranasal challenge and be able to grow on blood agar while the agglutination titre and the $\operatorname{ImD}_{50}$ of the protective antigen remain practically unchanged. The same lack of uniformity is found with biochemical characters.

Table 1. Comparison of characteristics of strains of Bordetella pertussis

\begin{tabular}{|c|c|c|c|c|c|c|}
\hline Strain & $\begin{array}{l}\text { Simplest } \\
\text { growth } \\
\text { medium }\end{array}$ & $\begin{array}{l}\text { Agglutina- } \\
\text { tion by } \\
\text { phase I } \\
\text { antiserum }\end{array}$ & $\begin{array}{l}\text { Growth in } \\
\text { autoclaved } \\
\text { cysteine }\end{array}$ & $\begin{array}{c}\text { Growth } \\
\text { with } \\
\text { 'peroxide' }\end{array}$ & $\begin{array}{l}\text { Formation } \\
\text { of arginine } \\
\text { and orni- } \\
\text { thine from } \\
\text { glutamate }\end{array}$ & $\begin{array}{l}\text { Presence } \\
\text { of urease }\end{array}$ \\
\hline Phase I & BG & ++ & - & - & - & - \\
\hline 'Pertussis A' & Blood agar & + & Slow & - & - & - \\
\hline CN2217 & Digest agar & + & Slow & - & - & - \\
\hline NCTC364 & Digest agar & - & Slow & - & - & - \\
\hline G146E & Digest agar & - & Slow & $?+$ & + & + \\
\hline G154E & Digest agar & - & Slow & $?+$ & + & + \\
\hline
\end{tabular}

I (Rowatt, unpublished) have studied 5 strains of Bordetella pertussis which are degenerate to a greater or lesser degree (Table 1). The smoothest of these, 'Pertussis A', is the strain used by Pollock (1947), which did not grow on digest agar but grew quite well on blood agar and did not have to be sown very thickly for growth. It was agglutinated by phase I antiserum to a lower titre than a true phase I strain. The five strains were all tested for growth in Cohen \& Wheeler's medium to see whether they were inhibited by autoclaved cysteine, and in $0 \cdot 1 \%(\mathrm{w} / \mathrm{v})$ Casamino Acids to see whether peroxides were inhibitory. Growth of 'Pertussis A' in liquid media was slowed but not completely inhibited by autoclaved cysteine and the organism did not grow in $0.1 \%(\mathrm{w} / \mathrm{v})$ Casamino Acids unless blood was added, i.e. it was inhibited by 'peroxides' (Rowatt, 1957).

The strain CN2217 (Wellcome Research Laboratories Collection) obtained from Mr H. Proom is a degraded culture of CN 1262, the American 'Challenge' strain, growing on digest agar. The organisms were rather longer and thinner than those of other strains of Bordetella. It did not grow very easily on meat digest agar, tending to form blobs of mucoid material where the inoculum was thickest. It was difficult to emulsify and appeared to grow into the surface of the agar so that the topmost layer was taken off with the bacteria. It grew slowly in Cohen \& Wheeler's medium autoclaved with cysteine, but quite quickly when filtered cysteine was added after autoclaving the basal medium. It grew very slowly or not at all with $0 \cdot 1 \%(\mathrm{w} / \mathrm{v})$ Casamino Acids but at the normal rate when blood was added (Rowatt, 1957). The amino acids used 
during growth were the same as those used by phase I strains. This strain was agglutinated to a low titre by antisera against phase I strains.

The original phase IV strain of Leslie \& Gardner (1931) NCTC 364, was isolated before 1920 (Dr S. T. Cowan, private communication) and presumably was subcultivated more or less regularly from that date. It grew on digest agar, but again the growth was rather mucoid and not very profuse, although better than that of strain CN 2217. This strain was not agglutinated by antisera to phase I strains. It grew slowly in the presence of autoclaved cysteine but not with $0 \cdot 1 \%(\mathrm{w} / \mathrm{v})$ Casamino Acids.

The strains G154E and G146E grew profusely on digest agar, giving an easily emulsified growth on the plates and odour of diacetyl, and they grew from small inocula unlike strains NCTC 364 and CN 2217. The strains G 154E and $\mathrm{G} 146 \mathrm{E}$ grew on digest agar shortly after isolation from cases of whooping cough and were agglutinated to a titre of 1/500 by an antiserum against Bordetella parapertussis (Dr J. Ungar, private communication). However, they did not form any pigment on digest agar or in liquid media and were not typical $B$. parapertussis. At a later stage they were not agglutinated by antisera to $B$. parapertussis or to phase $\mathbf{I} B$. pertussis or to the other phase IV strains (Rowatt, unpublished). They agglutinated to titre with antisera to each other. These strains grew in the presence of autoclaved cysteine, but growth in $0.1 \%(\mathrm{w} / \mathrm{v})$ Casamino Acids was very much slower and was not improved by blood (Rowatt, 1957). This suggests that 'peroxide' was not the inhibitory factor in this case. The quantity of organisms formed was very small and it seemed that a growth factor was lacking. Strain G $146 \mathrm{E}$, indeed, grew very little even in $1 \%(\mathrm{w} / \mathrm{v})$ Casamino Acids and in many experiments in liquid media it did not produce visible turbidity for 10-14 days. Of the amino acids available during growth these two strains usually used only glutamate. Strain G $146 \mathrm{E}$ used very little of this but strain G154 E occasionally used glutamate and alanine. It may be remembered that the other amino acids were not used by the phase I organisms until all the glutamate had disappeared and it is possible that these two strains do not grow vigorously enough to use all the glutamate and consequently do not start to use the other amino acids. They did not ferment the common sugars.

\section{Formation of ornithine and arginine from glutamate}

G146E and G154E, when grown on digest agar, oxidized glutamate readily and formed small quantities of arginine and ornithine, as well as $\mathrm{CO}_{2}$ and ammonia (Baddiley, Rowatt \& Standfast, 1952). The ratio of glutamate-N to ammonia was only 0.65 compared with 0.76 obtained with phase I strains (Rowatt, 1955). The other phase IV strains which we have tested did not form enough arginine and ornithine to show on chromatograms of untreated supernatant culture fluid, although they could sometimes be seen when this was concentrated. Both these $\mathbf{G}$ strains contained an active urease.

These strains, G146 E and G154E, thus seemed to be more closely related to Bordetella parapertussis except in pigment formation from tyrosine and in agglutininogens. The other phase IV strains did not differ very much from 
phase I strains except in the important respect that they grew on agar without blood. All five were different and seem to support the idea of a gradual change from rough to smooth rather than the four steps suggested by Leslie \& Gardner (1931).

\section{Relationship to other species}

Bordetella parapertussis and $B$. bronchiseptica each resemble $B$. pertussis in using glutamate for growth and needing nicotinamide (Proom, 1955). They are also unable to use carbohydrates, differing in this from Haemophilus influenzae. B. parapertussis and B. bronchiseptica are not inhibited by colloidal copper sulphide (Proom, 1955) or by 'peroxide' (Rowatt, 1957). The antigens of the Bordetella organisms are related to each other (Eldering \& Kendrick, 1938; Kendrick, Nadolski, Eldering \& Baker, 1953) and they are not related to those of the Haemophilus group. B. parapertussis and B. bronchiseptica oxidize glutamate to $\mathrm{CO}_{2}$ and ammonia and again less ammonia is formed than should be from the glutamate used. B. parapertussis forms less ammonia than $B$. bronchiseptica and some of the missing nitrogen appears as arginine and ornithine (Rowatt, 1955). Both contain urease (Moreno-López, 1952). B. parapertussis differs from $\boldsymbol{B}$. bronchiseptica and $\boldsymbol{B}$. pertussis in forming a brown pigment during growth (Eldering \& Kendrick, 1938). Ensminger (1953) found that the pigment was formed from tyrosine. Washed suspensions formed a pink pigment from tyrosine in the presence of glutamate at $\mathrm{pH} \mathbf{7 \cdot 4}$ and the pink pigment turned brown on prolonged incubation (Rowatt, 1955). Bradford \& Slavin (1937) found catalase in B. parapertussis and B. bronchiseptica but not in $B$. pertussis. Later work has shown that the last organism generally and possibly always contains catalase (see above).

Each of these organisms grows on digest agar, Bordetella bronchiseptica rapidly and profusely and $B$. parapertussis less readily. B. bronchiseptica will grow from a small inoculum but it is necessary to use quite a large inoculum of B. parapertussis or it dies out (Rowatt, unpublished). Proom (1955) showed that Bordetella bronchiseptica is the least exacting of the three species, growing on an inorganic salts medium + nicotinic acid + glutamate + proline + leucine, although some strains also required cystine + methionine. All strains of B. parapertussis needed cystine and methionine. B. pertussis did not grow in this medium, although it grew when asparagine + alanine + serine + starch were added. As stated above, there is some controversy about adequacy of this medium for B. pertussis. B. bronchiseptica grew most rapidly of the three in the Cohen \& Wheeler type medium and this medium seemed to contain all needed growth factors. $B$. parapertussis grew more slowly and the growth rate decreased when growth was just visible (Rowatt, 1955). With small quantities of blood turbidity of $\boldsymbol{B}$. parapertussis became visible more quickly (Rowatt, $1957)$ and it is probable that $B$. parapertussis needs the factor present in blood which is required by $\boldsymbol{B}$. pertussis for rapid sustained growth (see p. 315). This requirement shows up more with $\boldsymbol{B}$. parapertussis, possibly because inocula of this organism were grown on digest agar without blood while those of $\boldsymbol{B}$. pertussis were grown on a medium containing $30 \%$ (v/v) blood. The 
liquid medium used may contain traces of the factor. In the Cohen \& Wheeler type medium $B$. bronchiseptica gives a greater turbidity for the same quantity of glutamate than the other two organisms (Rowatt, 1955), but it is possible that non-nitrogenous substances are also being used (Proom, 1955) and the efficiency is not really greater.

\section{Relation of the Bordetella group to other genera}

The three organisms of the Bordetella group are thus closely related. They have recently been separated from the Haemophilus group (Moreno-López, 1952; Proom, 1955; Pittman, 1955) on nutritional and antigenic grounds. On antigenic grounds (the common $\mathrm{O}$ antigen, toxin and site of infection) the division is valid. However, little is known of the metabolism of these organisms.

The pertussis organism was originally included in the genus Haemophilus because it was 'blood-loving'. The type organism of this genus, $H$. influenzae, required a heat-stable factor from blood (X-factor) and a heat-labile factor obtained either from blood or vegetable material (V-factor), and other strains in the group required one or both of these factors. Fildes (1923) showed that two strains of the pertussis organism would grow in peptone water without either X-or V-factor, and he wanted to exclude it from the genus. Certainly one, and probably both, of the strains which he used had been isolated 3 years previously (Dr S. T. Cowan, private communication) and were not in phase I. Hornibrook (1940) showed that Bordetella pertussis required nicotinamide which is a constituent of coenzyme I (DPN), and Jebb \& Tomlinson (1955) found an improvement of its growth in the presence of haemin. Haemophilus canis requires haemin for growth but not DPN, and it is possible, although it has never been proved, that this organism needs nicotinamide for growth. Classically $\boldsymbol{H}$. parainfluenzae does not need haemin for growth, but small inocula of this organism did not grow unless haemin or substances such as ferrous sulphate or manganese dioxide were added (Gilder \& Granick, 1948). These substances destroy peroxide and some of them exerted a sparing effect on haemin in the growth of $\boldsymbol{H}$. influenzae (Gilder \& Granick, 1948). Bordetella bronchiseptica and $\boldsymbol{B}$. parapertussis do not require haemin but both need nicotinamide (Proom, 1955), and thus from a nutritional point of view there is a case for including them in the same genus as the Haemophilus organisms.

The requirement for haemin under highly aerobic conditions is shared by Pasteurella pestis (Herbert, 1949), but this organism does not need nicotinamide for growth, and it needs a more complex amino acid mixture than the Bordetella group. The Brucella group use carbohydrates (McCullough \& Beal, 1951; Roessler, Sanders, Dulberg \& Brewer, 1952) and need thiamine, pantothenate and biotin for growth as well as nicotinamide (Koser, Breslove \& Dorfman, 1941). Brucella abortus and B. melitensis resemble Bordetella parapertussis and the two phase IV strains G 154 $\mathrm{E}$ and $\mathrm{G} 146 \mathrm{E}$ in forming arginine and ornithine from glutamate (Cameron, Holm \& Meyer, 1952), and Brucella abortus and, to a lesser extent, B. melitensis resemble Bordetella pertussis in being inhibited by autoclaved cysteine (Schuhardt, Rode \& Oglesby, 1949). 
There are thus similarities and differences between all four groups and until the metabolic characteristics are more fully understood they should not be made the basis of classification.

This work was carried out while the author was seconded from the Central Public Health Laboratory, Colindale.

The author wishes to thank Mr A. F. B. Standfast for instruction and criticism; and Drs W. H. H. Jebb and A. H. Tomlinson for making available their results before publication.

\section{REFERENCES}

Baddiley, J., Rowatt, E. \& Standfast, A. F. B. (1952). The metabolism of glutamate by some rough strains of Haemophilus pertussis. Proc. Int. Congr. Biochem. p. 75.

Balley, J. H. (1933). A medium for the isolation of Bacillus pertussis. J. infect. Dis. $52,94$.

Barksdale, I. S., Mullenix, G. K. \& Fuster, L. B. (1941). Further studies on a simplified cough-plate method for the early diagnosis of whooping cough. Sth. Med. Surg. 103, 176.

Barksdale, I. S. \& Simpson, F. P. (1934). A simplified cough-plate method for the early diagnosis of whooping cough. Sth. med. J., Nashville, 27, 943.

Barry, V. C., Conalty, M. L., Denneny, J. M. \& Winder, F. (1956). Peroxide formation in bacteriological media. Nature, Lond. 178, 596.

Border, J. \& Gengou, O. (1906). Le microbe de la coqueluche. Ann. Inst. Pasteur, 20,731 .

Bordet, J. \& Sleeswyx (1910). Sérodiagnostic et variabilité des microbes suivant le milieu de culture. Ann. Inst. Pasteur, 24, 476.

Bradford, W. L. \& Slavin, B. (1937). An organism resembling Haemophilus pertussis. With special reference to colour changes produced by its growth upon certain media. Amer. J. publ. Hlth, 27, 1277.

Cameron, H. S., Holm, L. W. \& Meyer, M. E. (1952). Comparative metabolic studies on the genus Brucella. 1. Evidence of a urea cycle from glutamic acid metabolism. J. Bact. 64, 709.

Cohen, S. M. \& Wheeler, M. W. (1946). Pertussis vaccine prepared with phase-I cultures grown in fluid medium. Amer. J. publ. Hlth, 36, 371.

Cruickshank, J. C. \& Freeman, G. G. (1937). Immunising fractions isolated from Haemophilus pertussis. Lancet, ii, 567.

Davis, B. D. \& Dubos, R. J. (1946). Interaction of serum albumin, free and esterified oleic acid and lipase in relation to cultivation of the tubercle bacillus. Arch. Biochem. 11, 201.

Dawson, B., Farnworth, E. H., McLeod, J. W. \& Nicholson, D. E. (1951). Observations on the value of the Bordet-Gengou medium for the cultivation of Haemophilus pertussis. J. gen. Microbiol. 5, 408.

Debré, R., Marie, J. \& Pretet, H. (1928). Les races de bacilles de Bordet-Gengou isolées à Paris. C.R. Soc. Biol., Paris, 98, 761.

Eldering, G. \& Kendrick, P. (1938). Bacillus para-pertussis: a species resembling both Bacillus pertussis and Bacillus bronchisepticus but identical with neither. J. Bact. 35, 561.

Ensminger, P. W. (1953). Pigment production by Haemophilus parapertussis. J. Bact. 65, 509.

Ensminger, P. W., Culbertson, C. G. \& Powell, H. M. (1953). Antigenic Hemophilus pertussis vaccines grown on charcoal agar. J. infect. Dis. 93, 266.

Farrell, L. \& TAylor, E. M. (1945). Notes on the production of phase I pertussis vaccine in fluid medium. Canad. J. publ. Hlth, 36, 326. 
Findes, P. (1923). The classification of haemoglobinophilic bacteria, based upon their relation to blood-pigment and to the 'vitamine' factor. Brit. J. exp. Path. 4, 265.

Fisher, S. (1948). The behaviour of Haemophilus pertussis in casein hydrolysate broth. Aust. J. exp. Biol. med. Sci. 26, 299.

Fujita, A. \& Kodama, 'T. (1934). Untersuchungen über Atmung und Gärung pathogener Bakterien. III. Mitteilung. Über Cytochrom und das sauerstoffübertragende Ferment, sowie die Atmungshemmung der pathogenen Bakterien durch CO und HCN. Biochem. Z. 273, 186.

Fukumi, H., Sayama, E., Tomizawa, J. \& Uchida, T. (1953). Nutritional requirements and respiratory pattern of pertussis-parapertussis-bronchisepticus group of microorganisms. Jap. J. med. Sci. Biol. 6, 587.

GrLder, H. \& Granick, S. (1948). Studies on the Haemophilus group of organisms. Quantitative aspects of growth on various porphin compounds. J. gen. Physiol. 31, 103.

Herbert, D. (1949). Studies on the nutrition of Pasteurella pestis, and factors affecting the growth of isolated cells on an agar surface. Brit. J. exp. Path. 30, 509.

Hinshelwoon, C. N. (1946). The Chemical Kinetics of the Bacterial Cell, 1st edn., p. 47. Oxford: Clarendon Press.

Hornibrook, J. W. (1939). Cultivation of phase I H. pertussis in a semi-synthetic liquid medium. Publ. Hlth Rep., Wash. 54, 1847.

Hornibrook, J. W. (1940). Nicotinic acid as a growth factor for $H$. pertussis. Proc. Soc. exp. Biol., N.Y. 45, 598.

JEBb, W. H. H. \& Tombinson, A. H. (1951). The catabolic activity of washed suspensions of Haemophilus pertussis. J. gen. Microbiol. 5, 951.

JebB, W. H. H. \& Tomlinson, A. H. (1955). The nutritional requirements of Haemophilus pertussis. J. gen. Microbiol. 13, 1.

Jebb, W. H. H. \& Tomlinson, A. H. (1957). The minimal amino acid requirements of Haemophilus pertussis. J. gen. Microbiol. 17, 59.

Kendrick, P. L., Nadolski, E. B., Eldering, G. \& Baker, J. (1953). Antigenic relationships of Haemophilus pertussis, the parapertussis bacillus and Brucella bronchiseptica as shown by cross protection tests in mice. J. Bact. 66, 166.

Kuein, J. R. (1940). The oxidation of $\mathrm{L}(-)$-aspartic and $\mathrm{L}(+)$ glutamic acids by Hemophilus parainfluenzae. J. biol. Chem. 134, 43.

Kimenko, W. N. (1908-09). Die Ätiologie des Keuchhustens. Zbl. Bakt. (Abt. 1 Orig.), 48, 64.

Koser, S. A., Breslove, B. B. \& Dorfman, A. (1941). Accessory growth factor requirements of some representatives of the Brucella group. J. infect. Dis. 69, 114.

Kristensen, M. (1927). Recherches sérologiques sur le bacille de la coqueluche. C.R. Soc. Biol., Paris, 96, 355.

Krumwiede, C., Mishulow, L. \& Oldenbusch, C. (1923). The existence of more than one immunologic type of B. pertussis. J. infect. Dis. 32, 22.

LACEY, B. W. (1951). Antigenic modulation of Haemophilus pertussis. J. gen. Microbiol. 5, xxi.

LACEY, B. W. (1954). A new selective medium for Haemophilus pertussis containing a diamidine, sodium fluoride and penicillin. J. Hyg., Camb. 52, 273.

Lawson, G. McL. (1939). Immunity studies in pertussis. Amer. J. Hyg. (B), 29, 119.

Leslie, P. H. \& Gardner, A. D. (1931). The phases of Haemophilus pertussis. J. Hyg., Camb. 31, 423.

McCullough, N. B. \& Beal, G. A. (1951). Growth and manometric studies on carbohydrate utilization of Brucella. J. infect. Dis. 89, 266.

Mackie, T. J. \& McCartney, J. E. (1953). Handbook of Practical Bacteriology, 9th edn., p. 189. Edinburgh: E. and S. Livingstone Ltd. 
Madsen, T. (1925). Whooping cough. Its bacteriology, diagnosis, prevention and treatment. Boston med. \& surg. J. 192, 50.

Mager, J., Traub, A. \& Grossowicz, N. (1954). Cultivation of Pasteurella tularensis in chemically defined media : effect of buffers and spermine. Nature, Lond. 174, 747.

Mazloum, H. A. \& Rowley, D. (1955). The growth requirements of Haemophilus pertussis on solid media. J. Path. Bact. 70, 439.

Mires, A. A. \& Misna, S. S. (1938). The estimation of the bactericidal power of the blood. J. Hyg., Camb. 38, 732.

Mishulow, L., Sharpe, L. S. \& Cohen, L. L. (1953). Beef-heart charcoal agar for the preparation of pertussis vaccines. Amer. J. publ. Hlth, 43, 1466.

Moreno-López, M. (1952). El genero Bordetella. Microbiol. esp. 5, 177.

Overend, W. G., Stacey, M., Webb, M. \& Ungar, J. (1951). The isolation of deoxyribonucleic acid from virulent and avirulent strains of Haemophilus pertussis. J. gen. Microbiol. 5, 268.

Pittman, M. (1955). The genus Bordetella Moreno-López, 1952. In Breed, R. S. et al. (1955). Symposium on Taxonomy. Bact. Rev. 19, 273.

Pollock, M. R. (1947). The growth of $H$. pertussis on media without blood. Brit. J. exp. Path. 28, 295.

Pollock, M. R. (1948). Unsaturated fatty acids in cotton wool plugs. Nature, Lond. 161, 853.

Pollock, M. R. (1949). The effect of long-chain fatty acids on the growth of Haemophilus pertussis and other organisms. Symp. Soc. exp. Biol. 3, 193.

Pollock, M. R., Howard, G. A. \& Boughton, B. W. (1949). Long-chain unsaturated fatty acids as essential bacterial growth factors. Substances able to replace oleic acid for the growth of Corynebacterium ' $Q$ ' with a note on a possible method for their microbiological assay. Biochem. J. 45, 417.

Pontwood, L. M. (1946). Catalase activity of Hemophilus pertussis. J. Bact. 51, 265.

Povitsky, O. R. (1923). Improved methods for the isolation and later cultivation of B. pertussis. J. infect. Dis. 32, 8.

Powell, H. M., Culbertson, C. G. \& Ensminger, P. W. (1951). Charcoal agar culture medium for preparing Haemophilus pertussis vaccine. Publ. Hlth Rep., Wash. 66, 346.

Proom, H. (1955). The minimal nutritional requirements of organisms of the genus Bordetella López. J. gen. Microbiol. 12, 63.

Proom, H. \& WoIwon, A. J. (1949). The examination, by partition paper chromatography, of the nitrogen metabolism of bacteria. J. gen. Microbiol. 3, 319.

Roberts, R. B., Cowie, D. B., Abelson, P. H., Bolton, E. T. \& Britten, R. J. (1955). Studies of biosynthesis in Escherichia coli. Publ. Carneg. Instn, 607, Washington D.C.

Roessler, W. G., Sanders, T. H., Dulberg, J. \& Brewer, C. R. (1952). Anaerobic glycolysis by enzyme preparations of Brucella suis. J. biol. Chem. 194, 207.

RowatT, E. (1955). Amino acid metabolism in the genus Bordetella. J. gen. Microbiol. 13, 552.

Rowatт, E. (1957). Some factors affecting the growth of Bordetella pertussis. J. gen. Microbiol. 17, 279.

Schuhardt, V. T., Rode, L. J. \& Oglessy, G. (1949). The toxicity of certain amino acids for brucellae. J. Bact. 58, 665.

Schuhard', V. T., Rode, L. J., Oglesby, G. \& Lankford, C. E. (1950). The development of peptone toxicity for brucellae with aging and the correlation of this toxicity with the probable oxidation of cystine. J. Bact. 60, 655 .

Schuhardt, V. T., Rode, L. J., Oglesby, G. \& Lankford, C. E. (1952). Toxicity of elemental sulphur for brucellae. J. Bact. 63, 123.

Silverthorne, N. \& Cameron, C. (1942). Whooping cough. IV. Beef liver extract blood agar media for growth of $H$. pertussis. J. Pediat. $20,16$. 
Snell, E. E. (1951). In Bacterial Physiology, p. 231. Ed. Werkman, C. H. \& Wilson, P. W. New York: Academic Press Inc.

Standfast, A. F. B. (1951). The phase I of Haemophilus pertussis. J. gen. Microbiol. $5,531$.

Toomey, J. A. \& McCleliland, J. E. (1933-34). Pertussis toxin or antigen. Proc. Soc. exp. Biol., N.Y. 31, 34.

Toomey, J. A. \& TaKacs, W. S. (1936). Changes in morphology of Hemophilus pertussis grown under varying conditions and on different mediums. J. Bact. 31, 44.

Toomey, J. A. \& Takacs, W. S. (1938). The effect of various blood mediums on the growth characteristics of $H$. pertussis. J. infect. Dis. 62, 297.

Tristram, G. R. (1946). Observations upon the application of partition chromatography to the determination of the monoamino-acids in proteins. Biochem. J. 40, 721.

Ungar, J., James, A. M., Muggleton, P. W., Pegler, H. F. \& Tomich, E. G. (1950). The cultivation of Haemophilus pertussis in partially defined liquid media. J. gen. Microbiol. 4, 345.

Verwey, W. F., Thiele, E. H., Sage, D. N. \& Schuchardt, L. F. (1949). A simplified liquid culture medium for the growth of Hemophilus pertussis. J. Bact. 58, 127.

Weichsel, M., Rubin, H. J., Cohen, P. \& Lapin, J. H. (1940). Intracutaneous tests with pertussis 'toxin' and complement fixation tests in whooping cough. Amer. J. Dis. Child. 60, 862.

Wilson, R. J. (1945). The production of phase I Pertussis vaccine in casein hydrolysate broth. Canad. J. Publ. Hlth, 36, 321.

Wittler, R. G. (1951). The L-form of Haemophilus pertussis. J. gen. Microbiol. 5, 1024.

Wittler, R. G. (1952). The L-form of Haemophilus pertussis in the mouse. J. gen. Microbiol. 6, 311.

Worwod, A. J. (1954). The inhibition of bacterial growth by colloidal heavy metal sulphides and by colloidal sulphur. J. gen. Microbiol. 10, 509.

W.H.O. Report (1953). Diphtheria and pertussis vaccination. Report of a conference of heads of laboratories producing diphtheria and pertussis vaccines. World Hlth Org. techn. Rep. Ser. no. 61. 